\title{
Handbook of Research on Mobile Devices and Applications in Higher Education Settings
}

Laura Briz-Ponce

University of Salamanca, Spain

Juan Antonio Juanes-Méndez

University of Salamanca, Spain

Francisco José García-Peñalvo

University of Salamanca, Spain

A volume in the Advances in Mobile and Distance

Learning (AMDL) Book Series 
Published in the United States of America by

Information Science Reference (an imprint of IGI Global)

701 E. Chocolate Avenue

Hershey PA, USA 17033

Tel: 717-533-8845

Fax: 717-533-8661

E-mail: cust@igi-global.com

Web site: http://www.igi-global.com

Copyright (C) 2016 by IGI Global. All rights reserved. No part of this publication may be reproduced, stored or distributed in any form or by any means, electronic or mechanical, including photocopying, without written permission from the publisher. Product or company names used in this set are for identification purposes only. Inclusion of the names of the products or companies does not indicate a claim of ownership by IGI Global of the trademark or registered trademark.

Library of Congress Cataloging-in-Publication Data

Names: Briz-Ponce, Laura, 1977- editor. I Juanes-Mendez, Juan Antonio, 1959-

editor. I Garcia Peñalvo, Francisco José, 1971- editor.

Title: Handbook of research on mobile devices and applications in higher

education settings / Laura Briz-Ponce, Juan Antonio Juanes-Mendez,

Francisco Jose Garcia- Peñalvo, editors.

Description: Hershey, PA : Information Science Reference, 2016. I Includes

bibliographical references and index.

Identifiers: LCCN 2016003153| ISBN 9781522502562 (hardcover) I ISBN

9781522502579 (ebook)

Subjects: LCSH: Internet in higher education--Research. I Mobile

communication systems in education--Research.

Classification: LCC LB1044.87 .H3426 2016 I DDC 378.1/7344678--dc23

LC record available at http://lccn.loc.gov/2016003153

This book is published in the IGI Global book series Advances in Mobile and Distance Learning (AMDL) (ISSN: $2327-$

1892; eISSN: 2327-1906)

British Cataloguing in Publication Data

A Cataloguing in Publication record for this book is available from the British Library.

All work contributed to this book is new, previously-unpublished material. The views expressed in this book are those of the authors, but not necessarily of the publisher.

For electronic access to this publication, please contact: eresources@igi-global.com. 


\title{
Chapter 10 \\ Bespoke Mobile Application Development: Facilitating Transition of Foundation Students to Higher Education
}

\author{
Nevan Bermingham \\ Dublin Institute of Technology, Ireland \\ Mark Prendergast \\ Trinity College Dublin, Ireland
}

\begin{abstract}
Smartphone usage by students has increased rapidly over the last number of years, and it is expected that the utilisation of mobile applications in educational environments will continue to increase. This chapter focuses on a bespoke mobile application which aims to facilitate the transition of Foundation students to Higher Education in an Irish setting. Foundation students comprise of Access and International Students participating on pre-degree foundation courses. These students experience a major life change in making this transition and it is important that efforts are made to ensure a successful adjustment experience. Research suggests that mobile technologies can play a central role in this endeavour by offering support and access to particular information needs. This chapter will detail the design and development of a bespoke mobile application with such a purpose in mind and will also describe how the app was field tested with a cohort of incoming Foundation students in an Irish third level institute.
\end{abstract}

\section{INTRODUCTION}

Foundation Students - comprising International and Access students - have particular needs when they transition to higher education, and International Students in particular experience a range of personal, social and cultural difficulties with this transition (Smith \& Khawaja, 2011). In an Irish context, thirdlevel or tertiary level education refers to all education after second-level, encompassing higher education in universities and colleges (Department of Education and Science, 2004). In the Dublin Institute of

DOI: $10.4018 / 978-1-5225-0256-2 . c h 010$ 
Technology (DIT) the authors sought to investigate the benefits of providing Foundation Students with a bespoke mobile application tailored to their particular information needs. A bespoke mobile application is one with functionality that is designed to provide a solution to specific needs or a particular problem (Salz \& Moranz, 2013). Development of such a mobile application would generally require substantial financial investment and technological expertise. However, this chapter will focus on a low cost model that requires minimal computer know-how to produce and deploy a mobile application in a matter of weeks. The authors will show how such bespoke mobile apps can be developed using freely available online Integrated Development Environments which facilitate deployment on the dominant Apple (iPhones, iPads) and Android mobile platforms. This chapter with detail the app's design, development and deployment along with its evaluation with a cohort of Foundation students in the DIT.

\section{MOBILE APPS IN EDUCATION}

\section{Mobile Application Growth}

Since the mid 1990's, the mobile network industry has sought widespread adoption of services that utilise mobile data to generate a new source of revenue, focusing on the "mobile internet" and new mobile data solutions (West \& Mace, 2010). This emerging mobile internet was revolutionised by the entry into the market of the iPhone by Apple Inc. The device differed from its predecessors in that it incorporated a large intuitive touchscreen and relied on mobile users to sign up for a mobile data service plan to use its web browsing and internet capabilities. One of the iPhone's key innovation was the ability to allow third party application development which greatly increased the range of functions and applications available to the user through its App Store (West \& Mace, 2010). Since the launch of the iPhone, the mobile internet ecosystem has undergone a rapid transformation, and these changes have been driven primarily by improvements in the mobile network infrastructure, a rapid uptake in smartphones and a significant increase in the demand for mobile applications (Basole \& Karla, 2012).

On the back on the success of the iPhone, Google's entry into the market with Android based mobile phones and tablets has targeted the same consumers as iPhones. Google's strategy is to partner with handset vendors to provide consumers with a range of handsets across a broad range of price points all using the open source Android operating system. The success of Android has also seen an increase in market share and available apps (Butler, 2011).

Since 2010, Android tablets and Apple iPads are likewise capable of running apps in a similar fashion to smartphones, utilising the same operating systems as their smartphone counterparts. Currently tablet computing platforms can be divided generally into two categories, the Tablet PC platform based on a conventional PC architecture and the mobile multi-touch tablets such as Android Tablets and the Apple iPad (MacLean, Tausky, Labahn, Lank \& Marzouk, 2011). Research has shown that 34\% of American adults own an iPad or Tablet device, an increase of $31 \%$ since 2010, with college graduates being among the most likely to own one. The same research has shown that $33 \%$ of adults in the US aged between 18 and 24 years own a tablet device (Zickuhr, 2013).

With this growth in smartphones and tablets comes the emergence of the Apple App Store and the Google Play Store, the equivalent app store for Android smartphone and tablet users. This emerging app economy has revolutionised the creation and distribution of applications for mobile devices, and both commercial enterprises and hobbyist developers can easily access a market of hundreds of thousands 
of mobile users (Henze, Pielot, Poppinga, Schinke \& Boll, 2011). Basole (2009) and Basole and Karla (2012) argue that the mobile app store is particularly transformative in how value is being created, delivered and consumed. The mobile ecosystem has evolved from being network operator centric to being platform-centred.

A study carried out by Edmondson et al. (2014) has shown that consumers are buying fewer stand-alone desktop computers but are rather adopting new mobile technology. Over the last decade the worldwide popularity of smartphones has surpassed laptop and desktop purchases. Gartner (2015) has reported that in 2014 sales of smartphones to end users was at 1.2 billion units, an increase of $28.4 \%$ from 2013. This was driven by the availability of smartphones at lower prices which has accelerated the migration of feature phone users to smartphones. Gartner also reported that the Android operating system, which is used on Android smartphones, had an $80.7 \%$ worldwide market share in 2014, followed by Apple's iOS at $15.4 \%$.

Gartner (as cited in Baghdassarian, 2013) predicts that over the coming years mobile apps will become the official channel to drive content and services to consumers, and users will continue to adopt and interact with apps. The Pew Research Centre's Internet \& American Life Project has shown that in $201356 \%$ of adults in the US stated that their device is a smartphone. The remaining $35 \%$ stated that they own a mobile phone that is not a smartphone, with $9 \%$ stating they did not own a mobile phone (Smith, 2013). The same study suggests that college students are the most likely to be rapid adopters of smartphone and mobile technologies. There is a corresponding increase in tablet device ownership in the US - such as iPads and Android Tablets - from 3\% of adults in the US owning a tablet device of some kind in 2010, to 34\% of adults in the US owning a tablet device in 2013 (Zickuhr, 2013).

A study of technology ownership among Dutch students has shown that $96 \%$ of students own at least one mobile device - a laptop, tablet, or smartphone - and has also shown that ownership rates are consistently high for all groups of students, including lower income students (Kobus, Rietveld \& Van Ommeren, 2013).

\section{Student Technology Adoption}

With such high ownership rates of mobile devices for college students higher education is rapidly changing to accommodate students for whom technology is seen as having a significant influence (Kobus et al., 2013). There is evidence to suggest that technology facilitates easier communications for students as well as showing a positive influence on academic work and performance (Russo, Fallon, Zhang \& Acevedo, 2014).

Students entering education have been referred to as the "Net Generation" (Tapscott, 2008) mainly due to research which indicates that they are technologically savvy and their social networks have been established through the internet and the use of technology (Oblinger \& Oblinger, 2005). These students perceive technology to be at the core of their existence and have created a dependency on using this technology to feel connected. A recent study by the Educause Centre for Analysis and Research of 1.5 million students over 213 institutions across 45 US States found that students perceive technology to be embedded into their daily lives, and are inclined to have a favourable attitude to technology (Dahlstrom, Walker \& Dziuban, 2013). The study also found that mobile device usage is growing, and that these students are increasingly using these devices for academic purposes. They concluded that while technology is omnipresent in the lives of students, there remains a challenge for educators to leverage technology as a tool to engage students, and that students still have a complex relationship with technol- 
ogy in that they recognise its value, but rely on academics to provide guidance when it comes to using this technology in meaningful ways.

This desire by students to use technology is coupled with the growth in mobile applications, and driven by their desire to have their information needs addressed quickly, sometimes at the expense of accuracy (Oblinger, Oblinger \& Lippincott, 2005). Mobile apps provide students with a convenient and accessible platform for immediate relevant information retrieval and keeps them connected through the updates they receive in areas that interest them the most. One of the main reasons behind the growth of mobile app usage in third level is that students are accustomed to using these apps in their personal life and have an expectation that their third level institutions will also provide similar apps to help them navigate college services and resources (Gupta, Gop \& Kyei-Blankson, 2014).

While there is a challenge for most educators to manage the use of technology in the classroom, many institutes encourage the use of smartphones for connectivity, event advertisement and the promotion of the university brand among their students (Hingorani, Woodard \& Askari-Danesh, 2012). Although research points to technology being omnipresent in the lives of students - 9 out of 10 students rate themselves as having favourable technology inclinations - leveraging technology as a tool to inform and engage students in meaningful ways is still evolving (Dahlstrom et al., 2013).

One study that centred on college admissions indicates that mobile apps are increasingly popular among students when transitioning to third level, and these students will often turn to their mobile devices to help research a college (Cappex, 2012). The students in this study also stated a preference to download a college's mobile app or go to their mobile website, with $46 \%$ of students preferring to research college information through a mobile app, and 54\% preferring this information through a mobile website. In addition, $35 \%$ of students surveyed said they would like to use a location-enabled college mobile app replacing a more traditional campus tour. The study concludes by suggesting that third level institutes should develop mobile apps in addition to their traditional website as a tool to provide to prospective students with information, stating that the amount of students who preferred an app over a mobile website increased by $31 \%$ in 2012, and the percentage of US colleges who have an app increased from $13 \%$ in 2011 to nearly $28 \%$ in 2012.

Even among mature students mobile phone usage is almost universal, and there is evidence to show that these students are utilising their devices for communication, capturing ideas and experiences, and informal learning. One study concluded that whatever their age, students demonstrate clear expertise in the use of mobile technologies (Kukulska-Hulme et al., 2011). As a collective body, students own, or have access to, some of the latest mobile devices and the applications that come with them.

\section{DEVELOPING BESPOKE MOBILE APPLICATIONS}

The challenge in developing any kind of mobile application is that despite smartphones rapidly gaining popularity they do not yet utilise a standardised platform (Heitkötter, Hanschke \& Majchrzak, 2013). Mobile apps usually refer to native apps - mobile apps that are specifically designed for one particular platform such as Android or Apple's iPhone platforms - which begin with code written in a language such as Java, as is typical of the Android Platforms. Each platform involves different Software Development Kit (SDK) tools and Application Programming Interfaces (API's), as well as each platform having its own user-interface conventions (Charland \& Leroux, 2011). While native apps can benefit from optimal intergradation with their device's operating system, native development across several platforms can be 
time consuming, costly and require specific coding skills (Heitkötter et al., 2013). This need to develop apps on various platforms using different software development kits can lead to fragmentation, which is defined as the inability to create one application that can operate on multiple platforms. This fragmentation can result in increased testing, project management and change management efforts (Rajapakse, 2008).

One solution to these problems is to produce web-based applications that are essentially mobile websites that look and feel like a native mobile application. However, while convenient and quick to deploy they have limitations that can make them unsuitable when increased functionality is required within the app (Christ, 2011).

Hybrid cross platform development approaches have emerged that combine the advantages of native and web development that allow for cost effective single implementation across multiple platform app development (Georgiev, Jana \& Shmatikov, 2014; Mao \& Xin, 2014). This class of applications, which are sometimes referred to as cloud-mobile hybrids, utilise heavy computations on the back end cloud based host system and mobile device based front-end application. The front-end and back-end components are collectively considered to be one single application in terms of the overall user functionality despite being in effect two independent applications (Manjunatha, Ranabahu, Sheth \& Thirunarayan, 2010).

While there are many web based development environments that a mobile app builder can now use, mostly for a monthly fee, there are development platforms available that allow for the creation of a simple cloud based information application with no requirement for coding skills at a very low cost. These development environments allow developers to create mobile applications via a simple web interface by selecting prebuilt modules that combine together in an 'à la carte' fashion. While functionality can be limited to the modules that are available, the range of modules available with these platforms allow for an easily developed app that performs well and has the same feel as a native app, and could be deployed across Apple and Android apps stores with ease. The main advantage of hybrid apps is the ability to run the source code over a wide range of platforms and a detailed knowledge of coding on the target platforms is not required (Xanthopoulos \& Xinogalos, 2013).

Christ (2011) states that before beginning the development of any cloud-mobile hybrids application, it is recommended best practice that a strategy be defined to help identify the application's scope, usability, and schedule to help deliver an application within the time constraints that meets the end users' needs. This strategy should:

- Determine Which Platforms to Deploy On: For the app created in this study, the dominant platforms of Apple and Android were the destination platforms.

- Develop 'Use Cases': Define the user types and their needs to determine what information or functionality the application must provide, including the designing of the user interface so that users can navigate the application easily.

- Create a Release Timeline: While cross-platform application deployment can involve longer timelines than releasing a single application, hybrid apps are by nature multi-platform and deployment across multiple platforms can happen simultaneously. However, most application stores require developers to submit the application for review, which can mean extra preparation and increased time to market.

However, it must be pointed out that hybrid applications are not without their challenges, and these considerations must be balanced against the lower cost (Prasad, Gyani \& Murti, 2012). Such challenges include: 
- Performance: Hybrid apps lack adequate performance for more demanding applications, and there is a dependency on the mobile network's performance which can result in the end user experiencing latency and delays.

- Security and Privacy: Information contained in the mobile app is hosted on external devices, not the app itself, and as such legal issues arise in the case of hybrid app providers exporting and storing user's data to other legal jurisdictions. This can create issues relating to the ownership of data and liability for its loss or misuse.

- Bandwidth Costs: The end user bears the cost for the hybrid app connecting to the internet to obtain its content, and this could grow substantially for data-intensive applications.

- Reliability: Hybrid mobile apps do not guarantee full uptime as the hosting computing service that holds the apps' information could suffer outages.

- Range of Mobile Could Development Platforms: Each development platform has its own development environment with different Application Programming Interfaces (API's) and languages. This locks the developer into a particular mobile cloud service vendor making portability across hybrid development platforms difficult (Manjunatha et al., 2010)

Despite such challenges, research points to the implementation of hybrid mobile apps as a promising cross-platform development solution for building generic apps which can be distributed with much lower cost and difficulty to the app stores of Apple and Google (Pastore, 2014; Xanthopoulos \& Xinogalos, 2013).

\section{THE PROCESS OF DEVELOPING A BESPOKE MOBILE APPLICATION}

This study will focus on a bespoke mobile application tailored to the particular information needs of Foundation students in DIT. As hybrid apps have a ubiquitous interface across all mobile operating system platforms, hence this study does not focus on the operating system, but on the functionality of the app itself. The primary function of the app is to orientate the students in advance of their arrival to the third level institution. Whereas m-Learning tools are primarily focused on how mobile technologies can be integrate into learning and teaching activities to provide instructional tools (Ozdamli, 2012), this bespoke application address the orientation needs of transition students. As such this mobile app is not classed as a m-learning tool, as m-learning tools employ a learning model that allows students to obtain learning materials anywhere and anytime using mobile technologies and the Internet (Lan \& Sie, 2010)

There are three main phases to the study:

Phase 1: Involves the design and development of this bespoke mobile application which is a low cost model that requires minimal computer know-how to develop. The authors will show how such bespoke mobile apps can be developed using freely available online Integrated Development Environments which facilitates deployment on the dominant Apple (iPhones, iPads) and Android mobile platforms.

Phase 2: Details deployment of the app with a cohort of incoming Foundation students in the DIT Access and International Foundation Programme in the 2014/15 academic year.

Phase 3: Concerns the evaluation of the app with this cohort of students. 


\section{Foundation Students}

Foundation students comprise Access and International students participating on pre-degree foundation courses. Established in 2012, DIT provides a yearlong Foundation Programme for International and Access students to acculturate and provide them with the skills necessary to transition effectively to higher education and undergraduate programmes within DIT. The Programme attracts over 170 International Students and 120 Access Students each year and provides them with a range of subjects designed to prepare students for their chosen undergraduate destination.

Access Foundation students in DIT are primarily made up of mature students (23 years of age or over) and young adult students (below 23 years of age) from socioeconomically and educationally disadvantaged backgrounds. In essence, Access students are "non-traditional" students. Schuetze \& Slowey (2002) state that the term "non-traditional" refers to socially or educationally disadvantaged sections of the population, which includes those from working class backgrounds, ethnic minority groups, immigrants and in certain cases, women. DIT's Access Student strategy is to ensure wider participation and equality of outcome in higher education by promoting access to higher education and facilitating Access students' participation and progression in DIT. DIT's growth target is 20\% for Mature Students and 7\% for Young Adult Access Students by 2020 (Dublin Institute of Technology, 2010).

Each year has seen an increase in International student mobility, and the global growth trends are positive (IHEQN, 2006). Approximately 1.7 million students, almost half of whom are from non-English speaking developing nations in Asia, cross borders every year to acquire a foreign education (Sawir, 2005). From an Irish context an International Student is defined as a "Third Country National", a person who is not an EU citizen and who is accepted by a higher education institute for the purposes of study in Ireland or other EU member state (Finn \& O'Connell, 2012). For Ireland, internationalisation has become a priority for both the higher education institutes and the Government, reflecting a need to compete at a global level for talent (Hazelkorn, 2011). The percentage of international students studying in the country has increased from 3\% in 2002 to 10\% in 2012 (Perkins, Shiel, Merriman, Cosgrove \& Morgan, 2013). The Government aims to increase this further as it bids to promote internationalisation and to significantly increase the proportion of fee-paying international students as a means to diversify the income base for higher education institutes (Department of Education \& Skills, 2010). This need to diversify the income base of institutions was further emphasised in the "National Strategy for Higher Education to 2030 Report" specifically referencing income generated from the recruitment of fee-paying international students (Hunt, 2011). This is estimated to be worth a total of $€ 1.2$ billion per annum, an increase of approximately $€ 300$ million on current levels.

Hunt (2011) states that the demand from students entering higher education directly from secondlevel increases only marginally, while the bulk of the increased demand will come from late entrants, mature students and international students. Mature students are those who are 23 or over when they enter higher education. Of these categories, the largest proportionate increase will be among mature students.

When students transition to third level, they experience a major life change, especially if this transition involves a move away from their home (Smith, 2014). Smith also argues that in this transition to a dramatically new environment they are also expected to perform academically whilst adapting to third level life, and states that reducing stress during this transition to college might help reduce experiences of depression and support the student better. Research suggests that International students are particularly prone to experiencing acculturative stress and difficulties with adjustment to the environment of the host country and third level, usually from a combination of language barriers, educational difficul- 
ties, isolation, discrimination, and practical problems associated with changing environments (Smith \& Khawaja, 2011).

Poyrazli and Grahame (2007) argue that third level institutions has a significant role in developing the resources needed to help International students have a successful adjustment experience. One particular piece of research indicated that mobile technologies can offer real advantages for students by making it as easy as possible for them to engage on their own terms with open access resources and that fostering new approaches with technology initiatives can ensure that the potential for enhanced student support can be fully exploited (Fotheringham \& Alder, 2012).

\section{Phase 1: Design and Development of the Mobile App}

The initial stages of designing and developing the app were identifying a cloud-mobile hybrid development platform, producing a project plan, and ascertaining the key resources required. Three people were placed on the development team based on the skills required - A content researcher, an app developer and a graphic designer. The purpose of the content researcher was to research and decide on what up to date information could be placed in the app. The graphic designer was an essential resource to work on the optics of the user interface and to ensure consistent branding to link the mobile app to existing on-line resources such as an associated blog and Twitter account. Evidence suggests that with webpage design there is a correlation between aesthetics and perceived usability which can positively affect user's impression of the site (Schultz, 2007). The app developer was tasked with implementing the content and graphics into the mobile app and deploying across Apple's App Store and Google's Play Store. Timelines and milestones were identified, as were inputs from other key personnel on the Programme, such as academics, outlined in Figure 1.

Once resources were identified and the timeline agreed, a requirements gathering phase was undertaken where the authors and stakeholders identified what information the students were likely to need and hence what functionality the app would need to provide. The app would be labelled "Prep4DIT" and

Figure 1. Project plan

\begin{tabular}{|c|c|c|c|c|c|c|c|c|c|c|c|c|c|c|c|c|c|c|c|c|c|c|c|c|}
\hline \multirow{2}{*}{ Tosk Nime } & \multirow{2}{*}{\multicolumn{3}{|c|}{22 Jun 14}} & \multicolumn{4}{|c|}{29 sun 14} & \multicolumn{3}{|c|}{ Cosul'14 } & \multicolumn{4}{|c|}{ is rot's } & \multicolumn{3}{|c|}{20 Jul 14} & \multicolumn{4}{|c|}{27 lua'18 } & \multicolumn{3}{|c|}{ QjAug 14} \\
\hline & & & & $\mathrm{T}$ & $s$ & $M$ & $w$ & $\boldsymbol{F}$ & $s$ & $\tau$ & $T$ & $s$ & $M$ & $w$ & 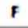 & 5 & $i$ & $\boldsymbol{T}$ & $s$ & $M$ & w & $\mathbf{F}$ & 5 & $\pi$ \\
\hline Design \& Content & & & & & & & & & & & & & & & & & & & & & & & & 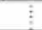 \\
\hline Interface Mockup & & & & & & & & & & & & & & & & & & & & & & & & \\
\hline App Build & & & & & & & & & & & & & & & & & & & & & & & & \\
\hline Testing & & & & & & & & & & & & & & & & & & & & & & & & \\
\hline - Deployment & & & & & & & & & & & & & & & & & & & & & & & & \\
\hline $\begin{array}{l}\text { Google Play } \\
\text { Store }\end{array}$ & & & & & & & & & & & & & & 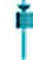 & & & & & & & & & & \\
\hline $\begin{array}{l}\text { Apple App } \\
\text { Store }\end{array}$ & & & & & & & & & & & & & & & & & & & & & & & & \\
\hline
\end{tabular}

Table 1. App requirements

\begin{tabular}{|c|c|c|}
\hline DIT Resources \& Campus Information & Staff Contact Information & Calendar of Key Dates \\
\hline Accommodation \& Visa Information & Travel Information & Living in Ireland Information \\
\hline Prep4DIT Blog & Twitter Feed \& Facebook & Information Videos \\
\hline
\end{tabular}


Figure 2. App navigation plan

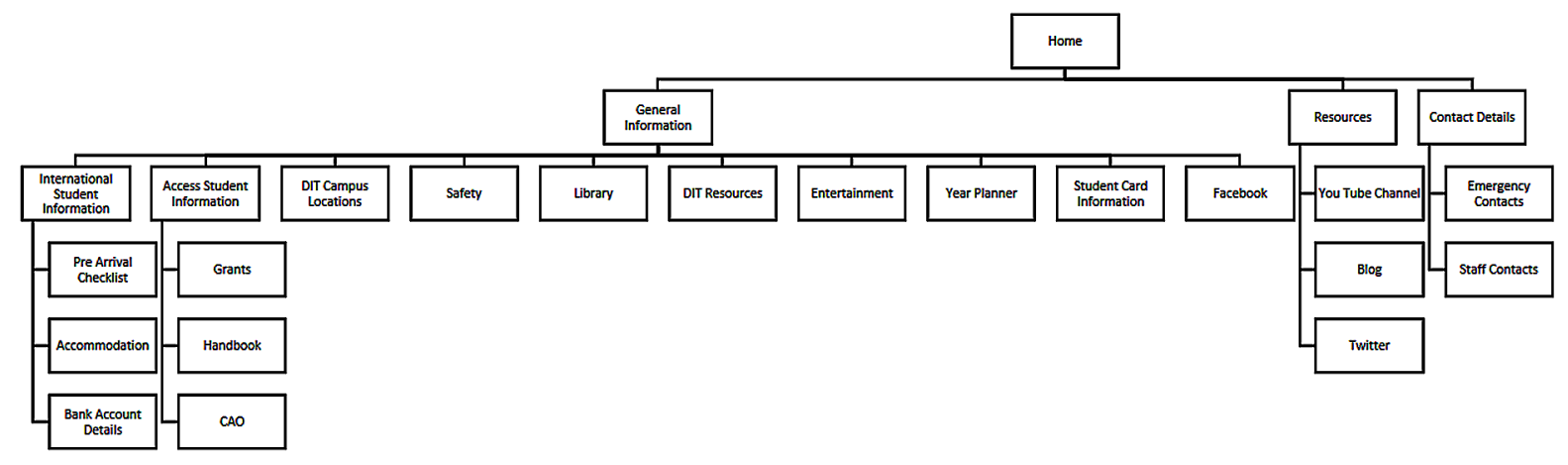

the design would match existing branding on literature and online resources. Nine requirements were identified as per Table 1 including DIT Resources \& Campus Information, Staff Contact Information and Living in Ireland Information.

Integration of the mobile app with existing web based tools - such as the Prep4DIT Twitter feed, YouTube Channel, Tumblr blog and Facebook page - was considered essential, as these tools would remain important to any students who did not have access to the app. This also had the advantage of allowing for real time content changes by many of the Programme's academic staff without the need to modify the actual contents of the app itself, as well as creating a 'one-stop shop' for all existing on-line resources.

Fling (2009) recommends that good design involves planning the navigation in advance of development to ensure there is a clear thought-out map of the ideal path the user will take to perform a task. This "clickstream" also serves to provide holistic bird's-eye view of the mobile information architecture. Figure 2 outlines the high level "clickstream" navigation plan for the Prep4DIT app.

The designers evaluated some of the on-line development platforms available for hybrid mobile applications utilising the criteria to compare each (Heitkötter et al., 2013):

1. Development Environment: Multiplatform capabilities for deployment to both Android and Apple App Stores.

2. Graphical User Interface (GUI) Design: Availability of tool to modify and apply bespoke graphics to the app and a WYSIWYG editor.

3. Ease of Development: Clear documentation with design examples and intuitive development interface to reduce the learning curve.

4. Maintainability: Ease by which the app could be updated and information changed.

5. Scalability: Being able to increase the scope of the app in content and functionality in the future.

6. Opportunities for Further Development: Reusability of project to other platforms.

7. Speed and Cost of Deployment: Factors that will match a rapid deployment.

Most online hybrid mobile app development environments allow the user to prototype and test their functionality before deployment and hence before any payment is made. After evaluating a few of these environments, the designers agreed that the platform provided by a British start-up company called "App Institute" (www.appinstitute.co.uk) offered similar functionality to other platforms on the market, but scored highest in the cost criteria in comparison to others. 
Figure 3. The development interface

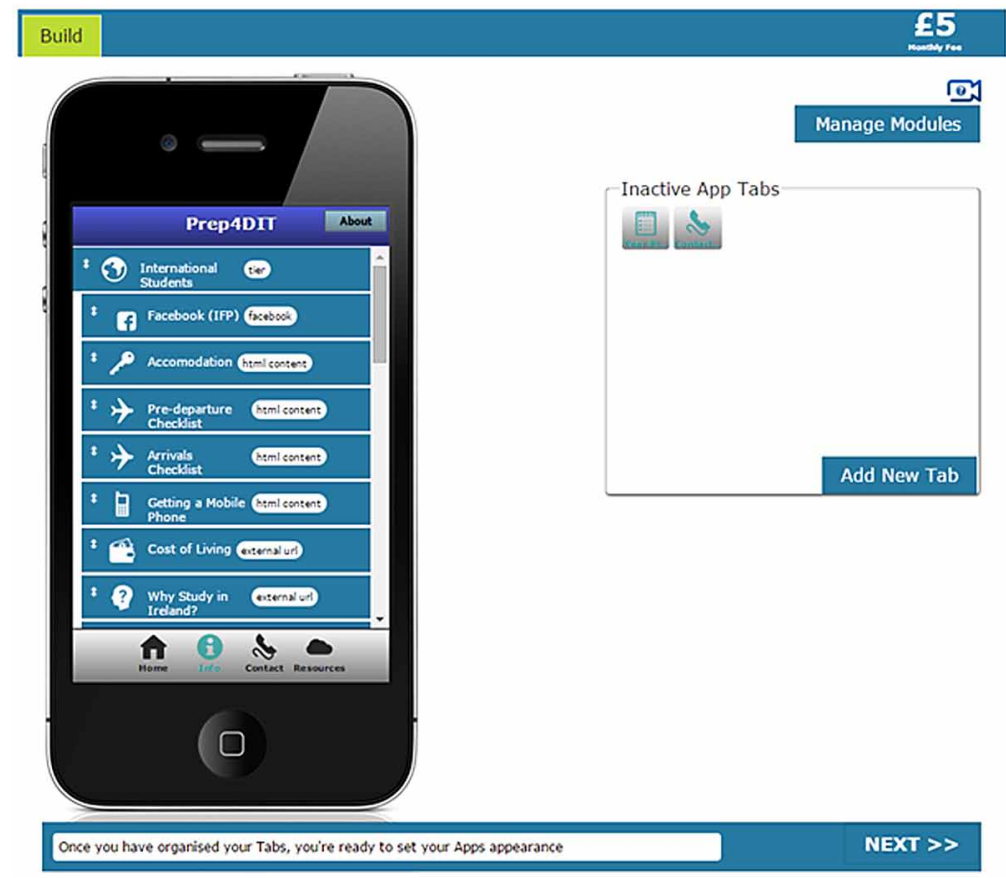

The App Institute development platform utilises modular components that encapsulate certain functionality - such as social media, HTML pagers, email feedback, maps - and each module is configured and "dropped" into the location on the on screen app preview, as shown in Figure 3. Each module can be organised in any order and its configuration edited to suit the content.

Once the mobile app was built to the meet the requirements agreed at the initial stages, it was then up to the graphic designer to create the colour scheme and icons. Figure 4 show the app interface configuration screen and the completed home page. The colour scheme was chosen to match the current branding of DIT.

\section{Phase 2: Deployment of Mobile App (Prep4DIT)}

The App Institute development environment provide testing functionality whereby the pre-release prototype version of the Prep4DIT app could be distributed to the testers - in this case the academic staff of the Programme - who could download a preview app from their respective app stores to allow them to view a fully functional version of the app. This allowed for the testers to evaluate the user experience and to feedback on any errors in content.

When the tester feedback was evaluated and changes implemented, the project moved on to the deployment phase. This involved setting up a Google Developers Account that allowed the developer to deploy the 'apk' file (Android Application Package) that was downloaded from App Institute to the Google Play Store. This involved a registration fee (USD\$25.00 as at $12^{\text {th }}$ May 2015). Deployment times to Google's live app market can vary, but are typically within a few hours. Deployment of the app through the Apple App Store involved utilising the internal publishing mechanism of the App Institute and the 
Figure 4. The design interface
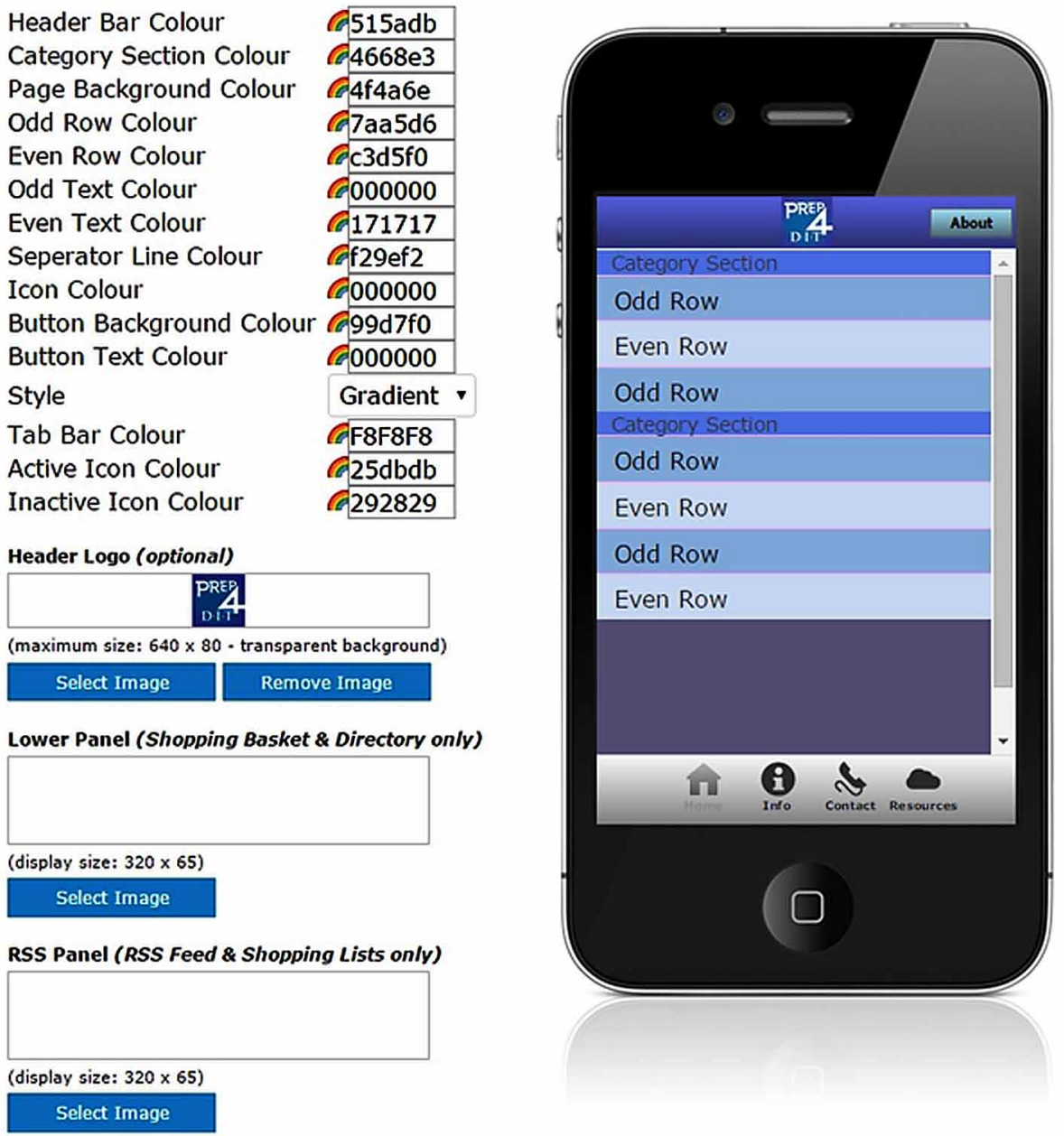

time to deploy was 14 days, which is longer than for the Google Apps Store due to Apple's evaluation criteria for new apps (Cuadrado \& Dueñas, 2012). The cost of an Apple Developer Account to publish the app on the Apple App Store was $€ 99.00$ (as at 12 ${ }^{\text {th }}$ May 2015).

It's important to note the key difference between the two app stores. Apple's App Store has a different approval and review process to Google's Play Store. While the deployment process is open to any submission, Apple employs multiple controls and filters before approving applications for release via the store. Apple manually inspects every submission by applying its defined review criteria, which can result in either approval and release to the market, or rejection of the application with a rationale for the decision. However, the Google Play approval process follows a different approach. Submitted applications are automatically checked for security concerns and immediately published to the market. The acceptance of the app on the market is checked through crowdsourcing and developers are liable for the submitted applications. App users detect and report unacceptable applications to Google via their internal reporting mechanism, and after sufficient reports are raised, any suspicious application is 
Figure 5. Prep4DIT in the Google Play Store

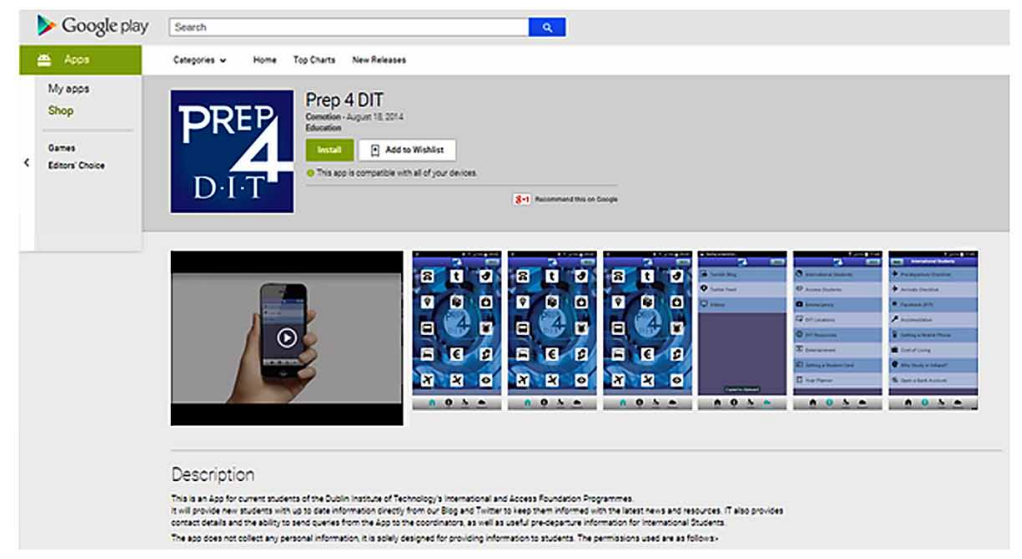

inspected by Google, and removed if the reviews are founded (Cuadrado \& Dueñas, 2012). Both stores require the submission of apps icons and screen shots, as shown in Figure 5.

Deployment of the app was live on the first week of August 2014 on both app stores. After the app was deployed, any changes made to the app via the App Institutes Developer Interface would be automatically reflected in the app itself. However, with the incorporation of the YouTube Channel, Blog and Twitter feed into the app, a wide range of individuals could contribute to the content without having to modify the app itself. An additional advantage to this approach was that it enabled students who did not download the app to view the same content online.

\section{Phase 3: Evaluation of PREP4DIT}

The third and final phase concerns the evaluation of the app. The app was evaluated with a group of incoming Access and International students onto the 2014-15 DIT Foundation Programme. The authors decided to use an explanatory sequential mixed methods design approach to evaluate the app by combining both quantitative and qualitative research. This use of multiple methods was decided upon in order to get an in-depth understanding of the quantitative findings through qualitative data. The collection and analysis of each type of data will be discussed in detail in this phase. The sample for the study was comprised of 91 students (65 from the Access cohort and 26 from the International cohort). All of these students were selected using a purposeful sampling method (the authors were given permission by one of the Foundation Programme lecturers to collect data in his Information Technology [IT] classes). As evidenced in Figure 6 there were fifty Irish students in the Access cohort and the remainder were from a range of countries including Romania and Ghana. The majority of International students were from Middle Eastern countries, with eighteen from Saudi Arabia and six from Oman.

The sample was made up of 64 male and 27 female students. As can be evidenced from Figure 7, there was a wide age range in the sample with the majority (34) of participants in the 17-23 age category. 21 of these 34 participants were International students. This accounts for $81 \%$ of the International cohort. The majority of Access students (37\%) were aged between 24 - 30 years. There were 3 female Access students aged between $51-60$ years. 
Figure 6. Nationality and programme type of sample

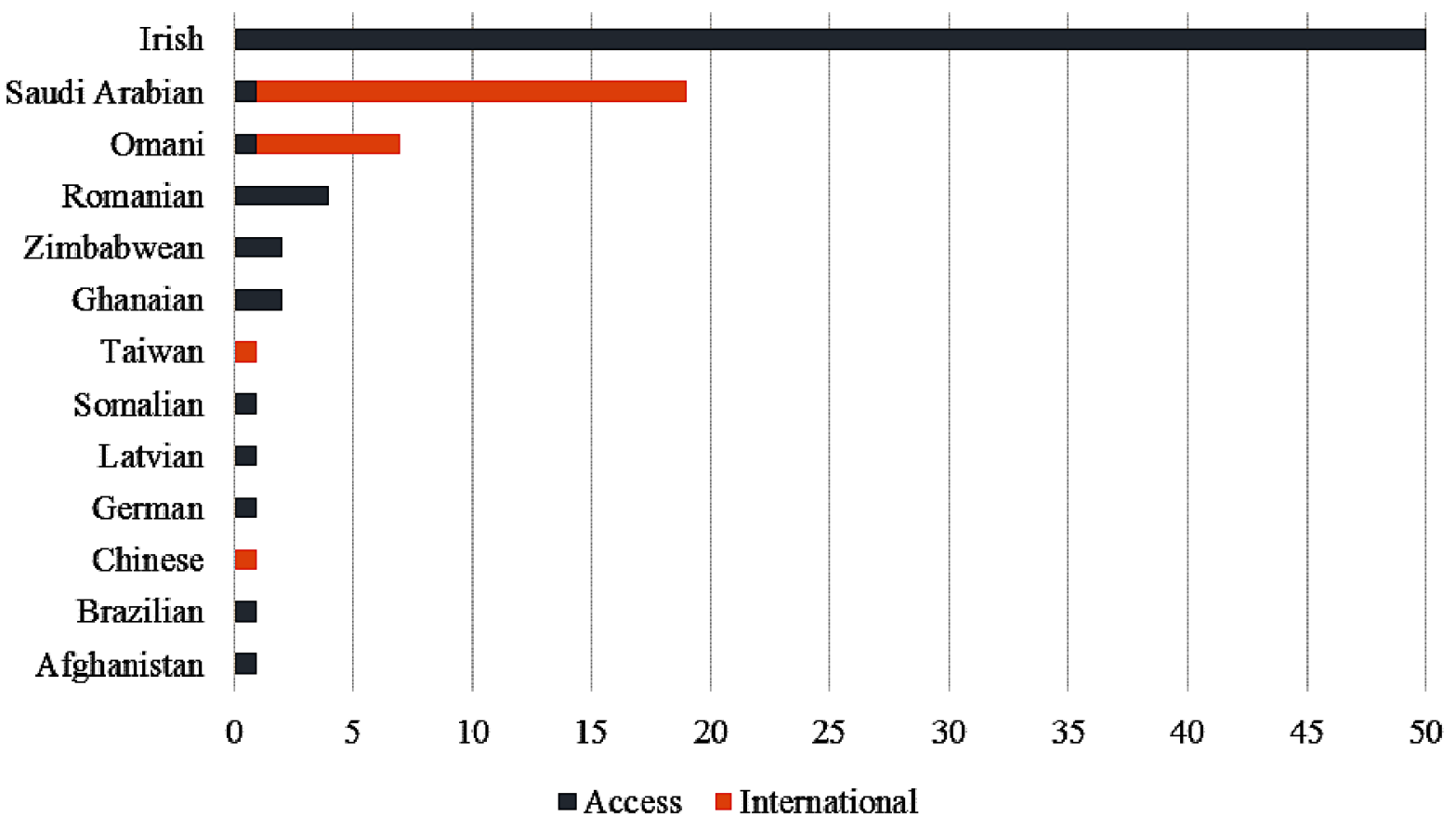

Figure 7. Age distribution, gender, and programme type of the sample

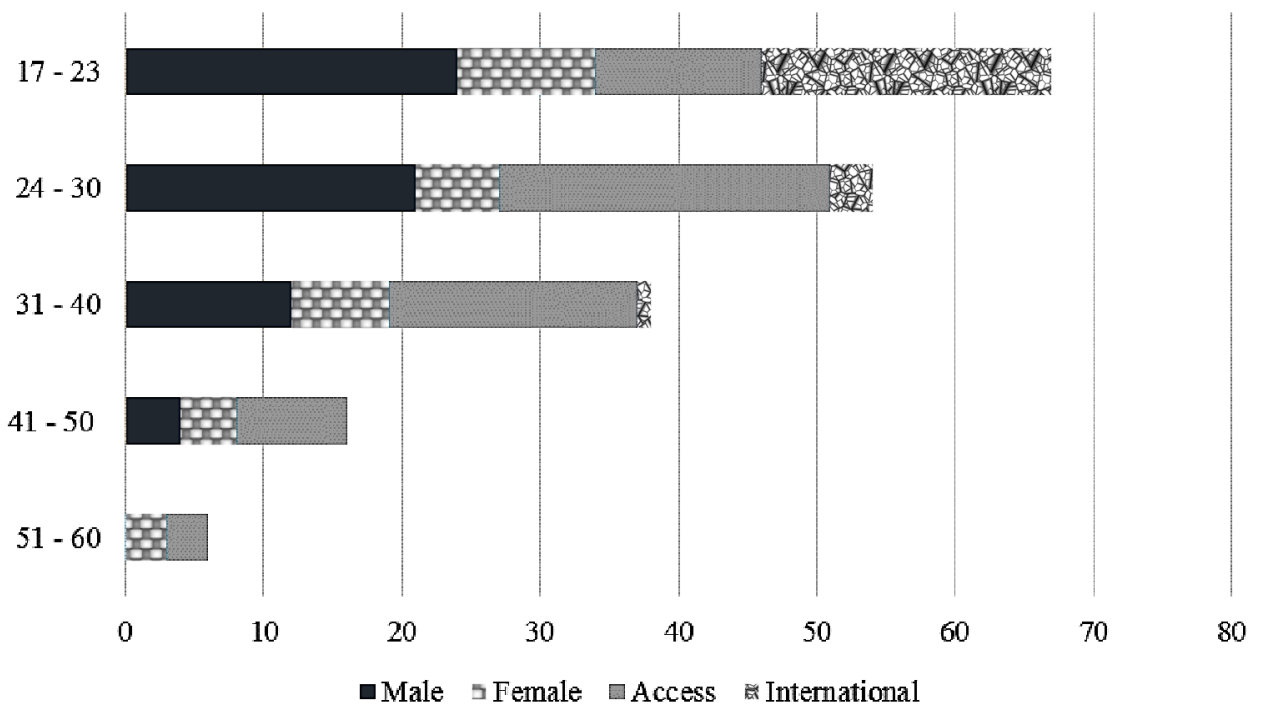




\section{Evaluation Using Quantitative Data}

The quantitative data was gathered through the use of a questionnaire which was developed by the authors. This questionnaire was piloted with eight students (four Access and four International students) prior to being distributed to the sampling cohort. This group of students were also enrolled on the DIT Foundation Programme and had access to the app. However, they were in a different IT class from the sample population and so were ideal candidates for piloting the questionnaire. There were some changes made to the questionnaire after the piloting phase. The majority of these focused around the length of the questionnaire and also the wording of some of the questions. It was important to keep the language to each question clear and concise so that it would not be misinterpreted by students with poor literacy skills or those for whom English was a second language. The final questionnaire was made up of three sections containing a mixture of closed and open ended questions. The final instrument was made accessible to the 91 participating students through an online form and all responses were saved to a password protected spreadsheet in Google Drive.

\section{Questionnaire Section 1}

The first section of the questionnaire began with collecting some background data on the participants such as their gender, age and nationality. It also focused on finding out more about their accessibility to smartphone devices and what types of app they normally use. Similar to other studies (Kobus et al., 2013), 86 of the 91 students who were surveyed owned a smart phone of some description. Of the 86,35 owned an iPhone and 45 an Android smartphone. This section of the questionnaire also listed the different types

Figure 8. App usage profile by category

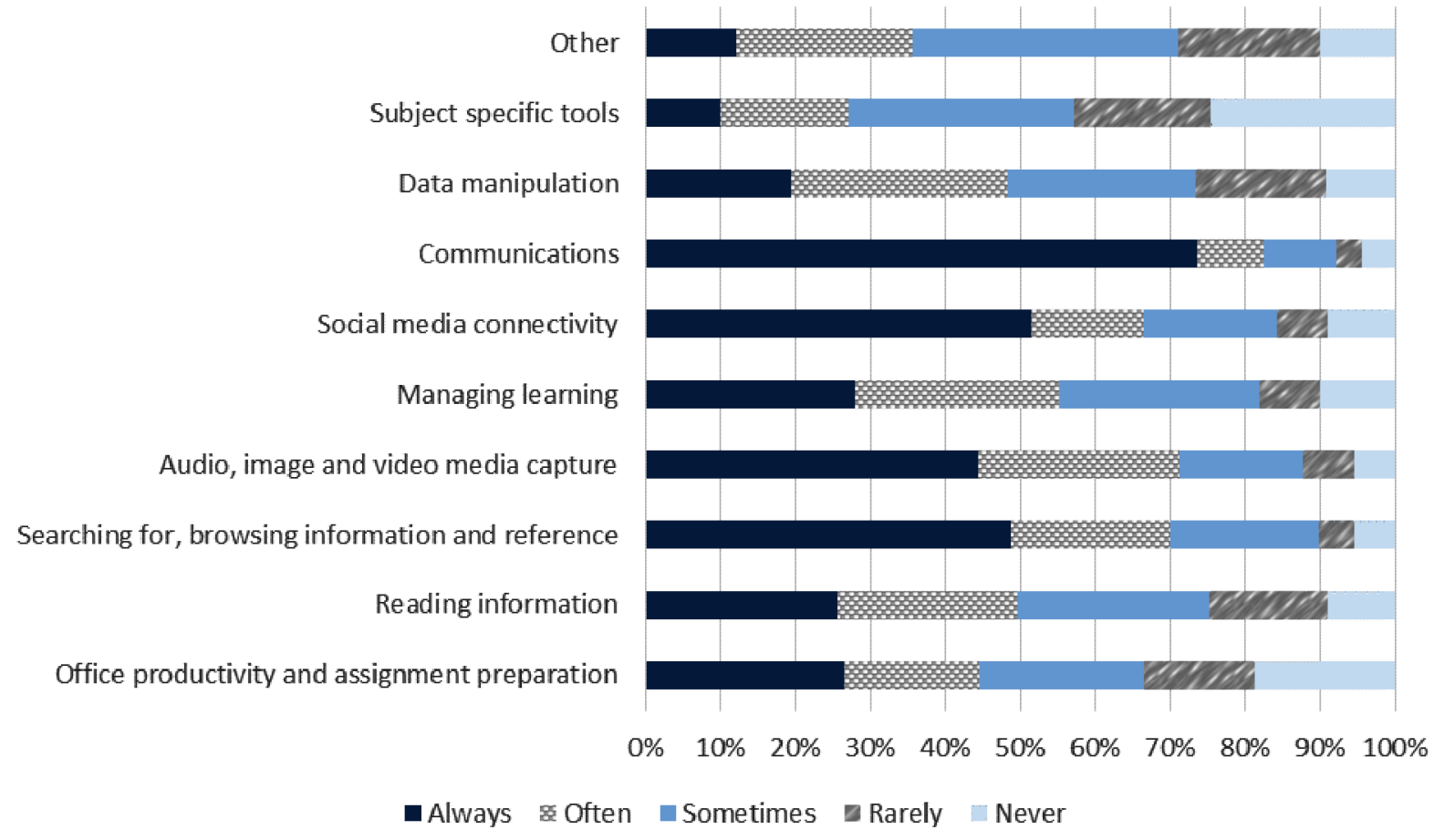


Figure 9. Months in which the Prep4DIT app was downloaded (access and international students)

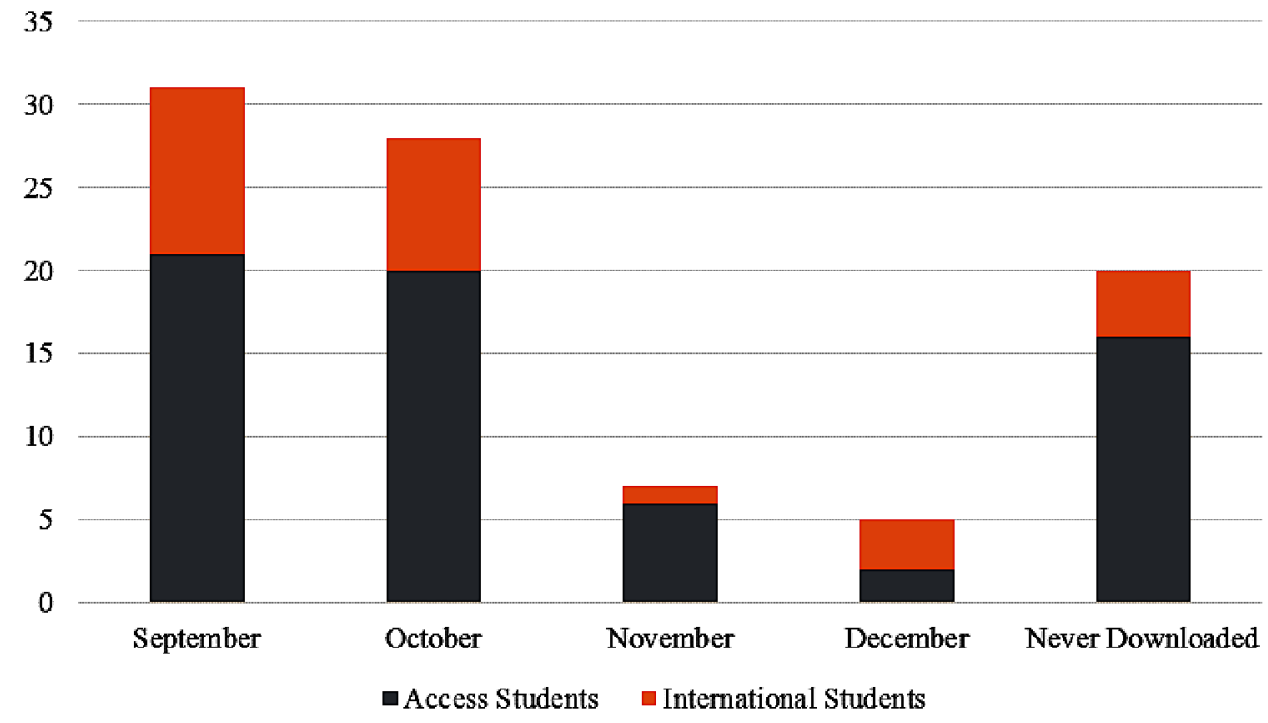

of apps available by category (Woodcock, Middleton \& Nortcliffe, 2012) and asked the students to rank how often they would them. Figure 8 shows that the most common types of app that students used were communications and social media connectivity, followed by searching for and browsing information. The least common types of app that students uses were subject specific tools and data manipulation.

\section{Questionnaire Section 2}

The second section of the questionnaire focused specifically on the PRE4DIT app. It investigated the times when the app was downloaded and the frequency of use per week. As can be seen from Figure 9, the majority of students (31) downloaded the Pre4DIT app in September at the beginning of the academic year. However 5 students did not download it until December and 20 students never downloaded the app. The majority of these (16) were Access students.

The questionnaire found that the majority of students (46) used the app between 1-4 times per week (see Figure 10). However, 28 students stated that they never used the app. Once again the majority of these students (21) were from the Access cohort.

The final part of Section 2 focused on the features of the app which students found to be most useful. These features differed for Access and International students and the evaluation reflected such differences. As Figure 11 denotes, International students found the location maps and the emergency contact features of the app to be the most useful. The YouTube Channel and the Entertainment features were found to be the least useful.

As can be seen from Figure 12, Access students on the other hand found the DIT resources and CAO (Central Applications Office) information to be the most helpful. Similar to their International counterparts they also found the YouTube Channel and the Entertainment features to be the least useful. 
Figure 10. Frequency of Prep4DIT app use per week (access and international students)

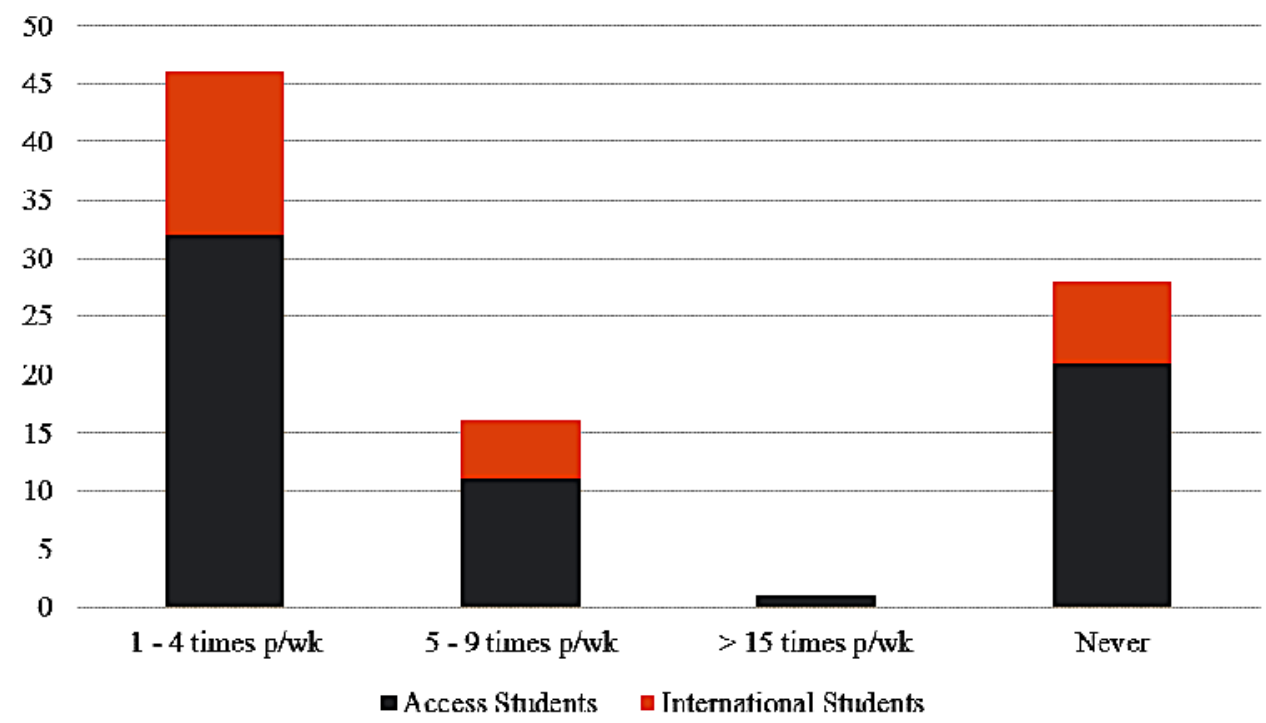

Figure 11. Usefulness of the app's features (international students)

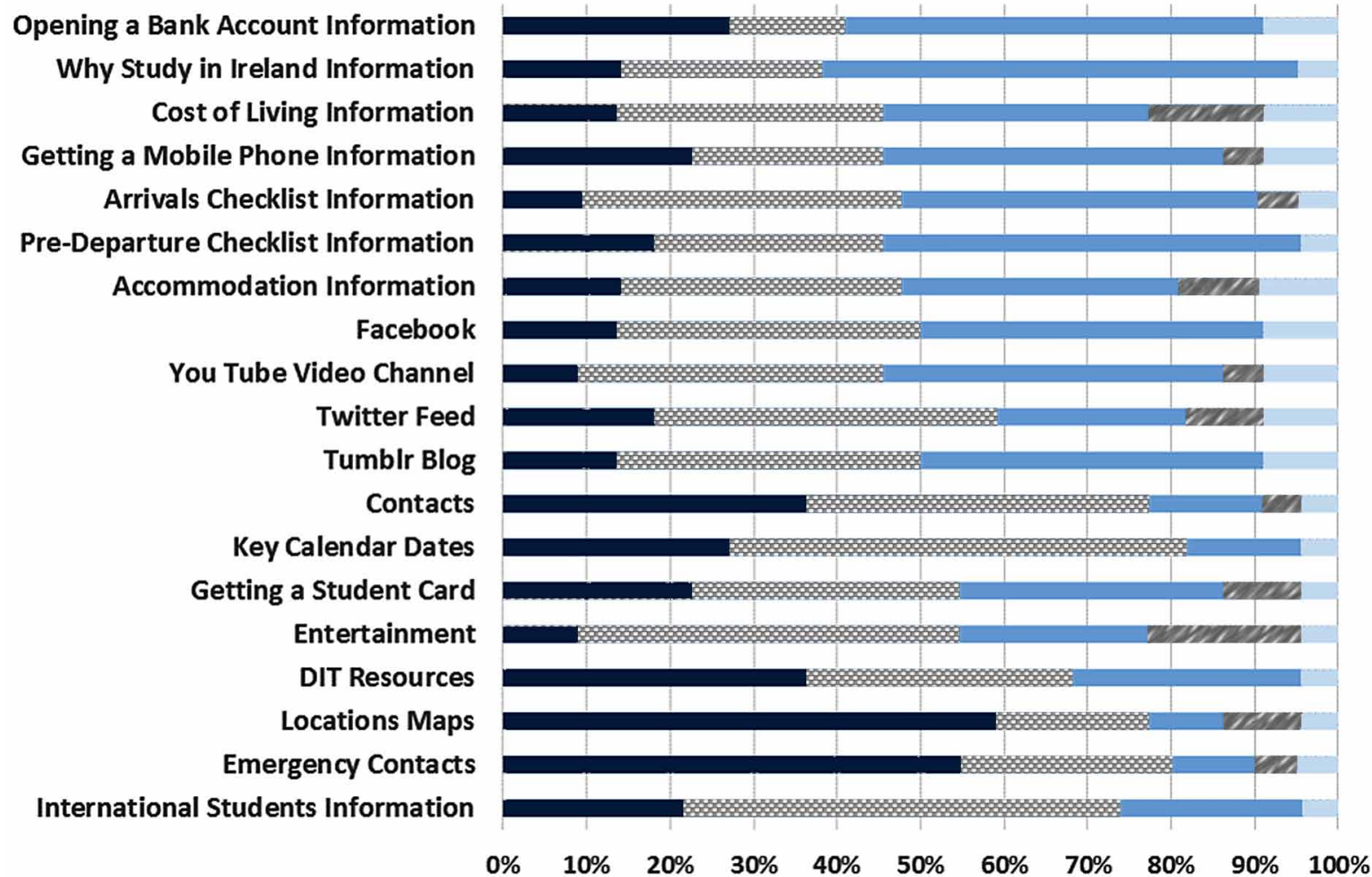

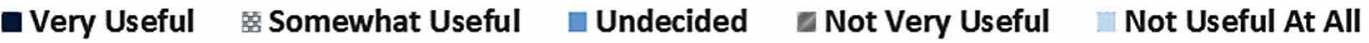


Figure 12. Usefulness of the app features (access students)

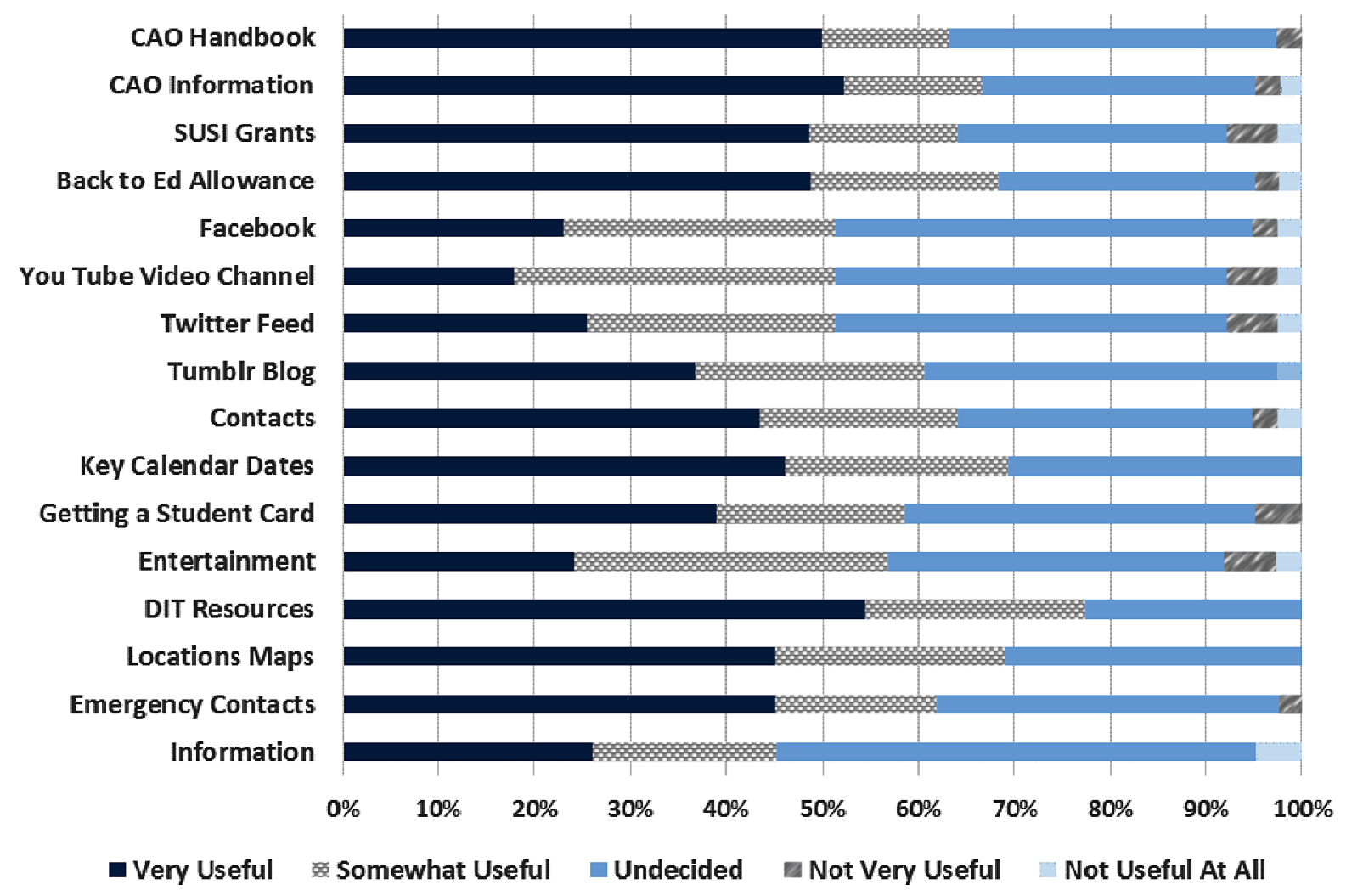

\section{Questionnaire Section 3}

The third and final section of the questionnaire comprised of a scale to measure student's attitudes towards the app. The authors could not find any scale for the evaluation of an educational app in the current literature. Hence they decided to develop a basic scale which evaluates the features of an educational app based on the elements that were found to be most important in the literature namely; user-friendliness; content accuracy, appearance/graphics, performance and reliability and student motivation (Schrock, 2011; Vincent, 2012).

The scale consists of 13 items, and respondents were asked to report the extent to which they agreed or disagreed with each statement on a scale of $1-5$. Seven of the statements in the scale are worded in the direction of a favourable attitude and the other six in the direction of an unfavourable attitude towards the app. Respondents were asked to indicate their level of agreement or disagreement with each item; 1 $=$ strongly disagree, $2=$ disagree, $3=$ undecided, $4=$ agree, $5=$ strongly agree. Scoring on negatively worded items was reversed (i.e. $1=$ strongly agree, $2=$ agree, $3=$ undecided, $4=$ disagree, $5=$ strongly disagree). Thus a high score would indicate a more favourable attitude towards the app. The highest possible score for the scale is 65 . The authors also looked at the reliability of the scale and found the Cronbach alpha coefficient to be 0.75 which indicates an acceptable level of internal consistency $(>0.7)$.

The overall mean score for the scale was 45.03 (SD: 6.51). Further descriptive analysis of the data in Table 2 highlights that overall students had a positive attitude toward the app. 
Bespoke Mobile Application Development

Table 2. Mean and standard deviation of each statement from scale (access and international students)

\begin{tabular}{|l|c|c|}
\hline \multicolumn{1}{|c|}{ Statement } & Mean & Std. Dev. \\
\hline I am not comfortable using the app* & 3.47 & 1.12 \\
\hline The app has given me confidence in using technology & 3.58 & 1.05 \\
\hline The app is easy to navigate & 3.60 & 0.94 \\
\hline The information displayed in the app is not always accurate* & 3.56 & 0.97 \\
\hline The app gives me a positive impression of the course & 3.81 & 0.84 \\
\hline Using the app provides me with timely and relevant information & 3.24 & 1.08 \\
\hline The aesthetics of the app are not visually appealing* & 3.23 & 1.03 \\
\hline The app is difficult to use* & 3.67 & 0.99 \\
\hline I was not given sufficient information on how to use the app* & 2.80 & 0.95 \\
\hline The app has made the transition to third level easier & 3.43 & 1.01 \\
\hline I like information about the course being available by app & 3.58 & 1.03 \\
\hline The app is not very reliable* & 3.67 & 0.91 \\
\hline I find the content of the app very useful & 3.37 & 1.06 \\
\hline
\end{tabular}

*The scores for these items were reversed i.e. a high score indicates a favourable attitude.

As can be seen from Table 2, the most positive response from students was that the app gives a positive impression of the course (3.81, SD: 0.84). The students also disagreed that the app is difficult to use (3.67, SD: 0.99$)$ and that the app is not very reliable (3.67, SD: 0.91). The least positive response was that students felt that they were not give sufficient information on how to use the app (2.80, SD: 0.95). A closer look at the data revealed some differences in the responses of Access and International students. The total mean score of the International students (M: 45.81, SD: 6.25) when compared to the Access students (M: 44.54, SD: 6.85) revealed that overall the differences were not statistically significant $(\mathrm{t}=$ $1.15, \mathrm{p}=.254)$. However as Table 3 reveals, the differences varied from statement to statement.

There were statistically significant differences in the responses of the Access and International students to two of the thirteen statements. International students (M: 3.54, SD: 1.14) agreed significantly more $(\mathrm{t}=1.68, \mathrm{p}=.047)$ than their Access counterparts $(\mathrm{M}: 3.12$, SD: 1.04$)$ that using the app provides them with timely and relevant information. International students also agreed significantly more $(t=2.79, \mathrm{p}$ $=.007)$ than Access students that they find the content of the app very useful.

\section{Evaluation Using Qualitative Data}

The qualitative data was gathered through the form of focus groups. Two separate focus groups were conducted by the authors with six International (P1 - P6) and five Access (P7 - P11) students. These students volunteered to take part in a follow-on discussion following the completion of the questionnaire. Each student was coded to ensure confidentially (P1 - P11). Their responses were transcribed, analysed and arranged into themes by the authors.

The positive findings of the quantitative data were reinforced through the responses of the focus groups. Overall students had a very positive impression of the app. 
Table 3. Mean and standard deviation of each statement from scale (international students only)

\begin{tabular}{|l|c|c|}
\hline \multicolumn{1}{|c|}{ Statement } & IFP Mean & AFP Mean \\
\hline I am not comfortable using the app* & 3.38 (SD:1.20) & 3.51 (SD:1.09) \\
\hline The app has given me confidence in using technology & 3.46 (SD:0.84) & 3.63 (SD:0.98) \\
\hline The app is easy to navigate & 3.69 (SD:0.90) & 3.60 (SD:0.98) \\
\hline The information displayed in the app is not always accurate* & 3.54 (SD:0.80) & 3.57 (SD:0.99) \\
\hline The app gives me a positive impression of the course & 3.92 (SD:1.14) & 3.77 (SD:0.86) \\
\hline Using the app provides me with timely and relevant information & 3.54 (SD:0.95) & 3.12 (SD:1.04) \\
\hline The aesthetics of the app are not visually appealing* & 3.42 (SD:1.24) & 3.15 (SD:1.06) \\
\hline The app is difficult to use* & 3.62 (SD:1.13) & 3.69 (SD:0.99) \\
\hline I was not given sufficient information on how to use the app* & 2.81 (SD:0.98) & 2.80 (SD:0.87) \\
\hline The app has made the transition to third level easier & 3.62 (SD:1.10) & 3.35 (SD:0.98) \\
\hline I like information about the course being available by app & 3.70 (SD:1.16) & 3.54 (SD:0.99) \\
\hline The app is not very reliable* & 3.73 (SD:0.72) & 3.65 (SD:0.98) \\
\hline I find the content of the app very useful & 3.85 (SD:1.05) & 3.18 (SD:1.01) \\
\hline
\end{tabular}

*The scores for these items were reversed i.e. a high score indicates a favourable attitude.

P9: In general I find the application very useful.

P2: the app in general is really good app and does many things.

P3: It's a good step for DIT to make life in DIT easier for international students.

One of the main themes that emerged from the data was the usefulness of the app for International students when they first arrive in the country and for Access students when they first begin college.

P5: it's very good for background and general information for DIT particularly at the start.

P7: It contained a lot of information for people who were new to Dublin or new to Ireland.

P3: I think the Prep4DIT helps particularly in the beginning of the course because it gives you a background about what you need to know about DIT.

According to participants the most useful aspects of the app were those that provided information on: Accommodation:

P3: In the beginning of the course I used it to search for accommodation. It led me to other websites which I may not have found.

P2: I was really struggling to find accommodation and it led me in the right direction.

P8: some people did not have accommodation and the app was helpful for them.

Library Opening hours:

P11: I found the opening hours of the library very good

P8: Opening hours for the library were really useful. 
Location / Layout of the campus:

P8: the campus locator was very helpful. I didn't have a clue where most of the buildings were.

P9: The location of the other DIT campus and directions were very useful.

Emergency Contact Numbers:

P5: if I'm sick or have a problem I can make contact with the hospital.

P4: the contact numbers for emergency situations to help the student is very useful.

Overall participants found that the app served as a very good 'access point' with all the relevant information and links in one place:

P10: all the information that you need for college is there and it's in front of you so you don't have to go searching through websites to find it.

One of the more interesting themes to emerge from the data is that entertainment features on the app such as Twitter and Facebook helped students to communicate with others through English and improve their language skills:

P2: things like Twitter and Facebook encourage to communicate with other students to improve your English. I have Irish friends now. The benefit of the app is making conversation with them and it improves our English.

Furthermore, they keep students engaged with other aspects of college life:

P7: I really liked the link to the Twitter feed. It had info like maths support groups and so on.

Another particularly pleasing and important finding to come from the focus groups was the impact that the app had on the first impressions of students registering on the Foundation Programme. This may be important in attracting Access and International students to the Programme in the future:

P8: when I saw it kind of made me realise that these people are serious about this course.

P11: I felt very impressed at first because it made me feel included in the whole thing.

However, despite the majority of positive feedback, participants of the focus groups also suggested some possible improvements for the app in the future. The main improvement centred on a particular graphic feature. The interface of the app comprises of a series of icons as options to navigate the app, as shown in Figure 13.

However, many of the students, particularly the International found these hard to recognise and would have liked a short description or some explanation for each icon. 
Figure 13. Primary app interface

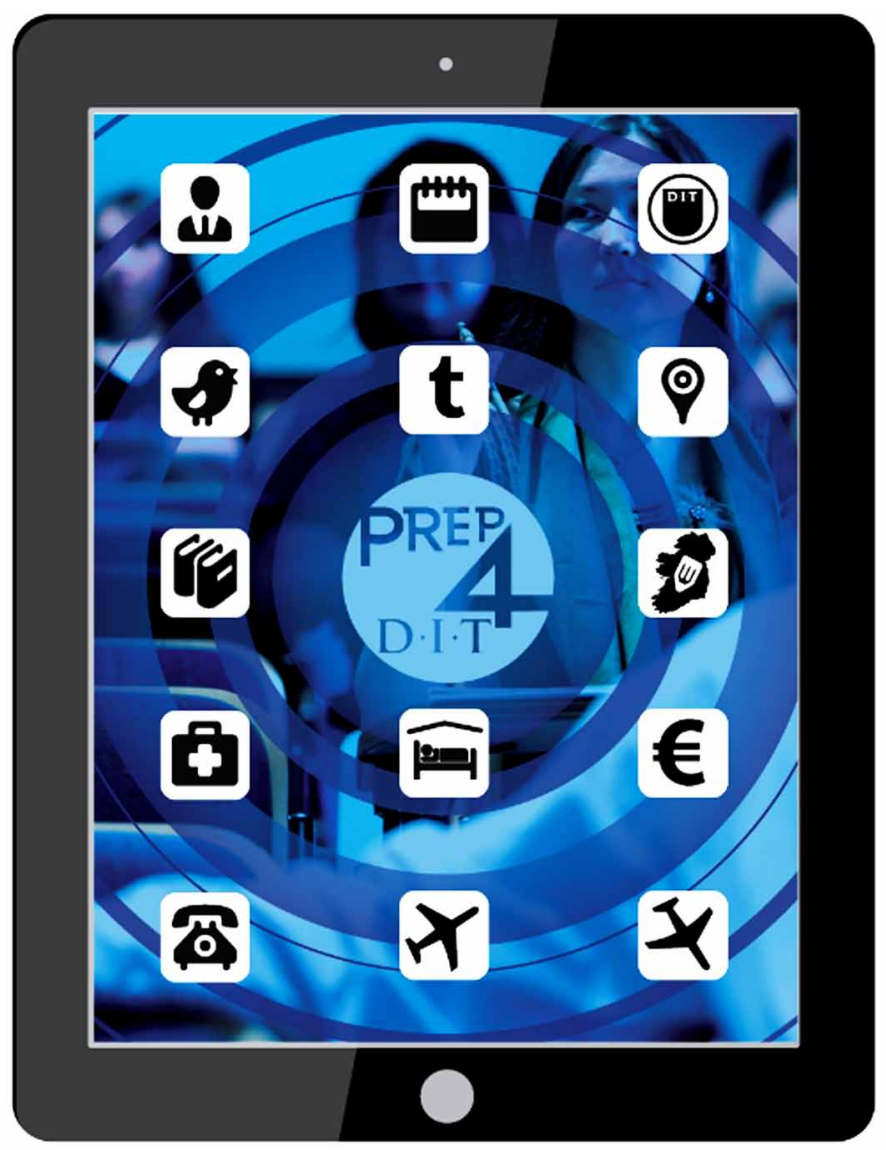

P1: it only gives you the picture, not the title of the features and sometimes this is difficult so I would like the writing as well.

P5: The only thing for all the icons to have small description.

P3: the clarity on the icons.

This is an interesting and helpful finding as it reminds the authors that icons which are considered self-explanatory for an Irish audience may not be familiar in an international context.

A common theme for improvement from the Access students was having more relevant up-to-date information provided on the App.

P11: if you could get information on the course you wanted to attend next year.

P7: I would like having a calendar link which notifies that our assignments were due.

P10: a live feed scenario on the front that would give you up to date information.

All of these suggestions are helpful and will be considered by the developers for inclusion in future modifications to the app. Figure 14 provides a summary of the qualitative data and outlines the main positives of the app and the main areas for improvements as suggested by the participants. 
Figure 14. Summary of the qualitative data

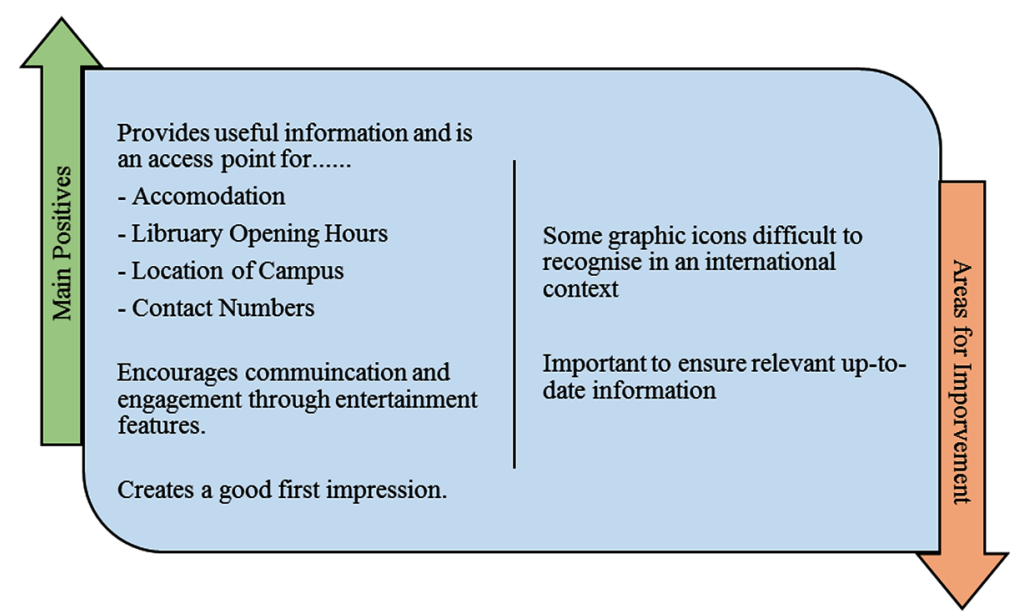

\section{Summary of Evaluation}

Overall the findings from both the qualitative and quantitative data are very encouraging and indicate a successful field-testing and evaluation of the app. The responses to the quantitative scale show that in general students held positive attitudes toward the app. The most positive statement was that the app gives a positive impression of the course. This point was also mentioned by students in the qualitative data. The least positive response was that respondents felt that they were not given sufficient information on how to use the app. A training session on how to use the app was conducted with students during their induction week. However the attendance was very low as many of the students were late registering for the Programme. In future, several training sessions should be done in the first few weeks of the Programme to ensure sufficient information is available to all students on how to use the app. Another noteworthy finding from the evaluation was that the earliest students downloaded the app was September, most likely after they had started the Programme. Next year a conscious effort should be made to encourage students to download the app before they begin college. This is where students will gain maximum benefit from the app. Developments in the design of the app should focus on improving the user interface to provide a better experience in intuitive usability for non-English speakers. In terms of the Access students a conscious effort must be made to provide more up-to-date relevant information. This was noted by the Access students in both the qualitative and quantitative data.

\section{DISCUSSION AND CONCLUSION}

In this chapter, the authors have shown that mobile applications for smartphones are becoming increasingly widespread and their usage is growing significantly. The advent of the high speed ubiquitous mobile internet has brought in a new market for developers in providing specific real-time point-of-need information to users in the form of mobile apps that are low cost and easily installed by the end user. Aided by the growth in cheap smartphones, there is evidence to suggest that smartphone and tablets are becoming the most common means by which users will access the internet in the future. Apple's App 
Store and Google's Play store have witnessed a steep increase in both app published and downloaded. This growth has seen consumers favouring mobile applications instead of desktop computers to do everyday tasks such as communicating, engaging in social media sites and browsing. As a result, many software developers are moving towards mobile applications development (Curran, McKelvey, Curran \& Nadarajah, 2015).

Ownership of smartphones among third level students is particularly high, and increasingly these students are using smartphones and mobile devices in their everyday lives in college (Kobus et al., 2013). The connectivity, ubiquity and wide range of functionality of these devices offers the potential for the use of smartphones for both education and information within the third level arena. These students have an eagerness and openness to use emerging technologies, and have an expectation that educational organisations are using these mobile technologies to inform and advise them in their college lives.

This chapter has shown that hybrid app development platforms offer academics and administrators a unique opportunity to deploy mobile apps that can provide a rich source of information for transition students to acculturate and prepare for third level. The traditional model of app development requires extensive coding skills and longer deployment times due to testing. However, these web based development platforms allow for a modular plug-in approach to constructing mobile apps that utilise many of the smartphones native features, without prior knowledge of web technologies like HTML, CSS and Javascript. This approach allows the apps to be deployed to both Apple's App Store and Google's Play Stores simultaneously without the need for programming languages and proprietary Software Development Kits (SDK's). Development platforms, like the App Institute used to create the Prep4DIT app, also allow for notification broadcasting which offers the functionality of real time short message communication with all students who have the app installed on their device.

The authors of Prep4DIT project demonstrate that the development time for hybrid mobile apps is much shorter than with traditionally coded native app models. In the case of the Prep4DIT app, concept to live deployment took under 2 months. The authors found that division of labour, such as engaging a graphic designer, can greatly improve the time to deployment. While there are costs involved in creating developer accounts for Apple and Google to deploy the app to their app stores, the overall cost of the Prep4DIT app was relatively low when compared with more traditional approaches to app development.

The results of field-testing and evaluation have shown that the app was seen as useful for International and Access students transitioning to DIT's Foundation Programme, with usage being greater at the start of term when the orientation information was most needed. In general, these students demonstrated a positive attitude towards the app as a means to inform and prepare them for third level, and it is important to note that the provision of mobile apps like Prep4DIT gave the students a positive view of the Programme they were undertaking. The information provided in the app that was seen to be of most use to students was campus locations, calendar dates, staff contacts and emergency contact information. This suggests a need by these students to feel comfortable in their new learning environment and to avoid problems that may arise from a lack of familiarity with the campus. One of the key development areas for future deployments of such an app would be to inform the students of the app at an earlier point before the term begins, perhaps with literature and a user guide included with the acceptance information normally sent to students, as well as including app demonstrations and training at the start of orientation.

While hybrid apps offer the non-technical developer an opportunity to innovate and deploy bespoke mobile apps, they are not without their limitations and caveats that potential developers need to be cognisant of. Hybrid apps development platforms are a one-size-fits all approach, and lack the rich functionality that can compete with natively developed apps. The functionality of the end product is directly 
dependant on the development platform for storage and provision of the information that is used within the app, and on mobile internet connectivity, which can result in diminished user experience caused by poor performance and loading errors. With the app content information being stored on the developer's platform, the security of this data must be considered. Further research is needed to explore these issues in relation to hybrid app development.

Another factor to consider in the context of the study is that while smartphone and mobile device ownership is very high among students, it may not be ubiquitous. The authors suggest that undertaking a mobile app project should integrate existing on-line resources into the development, rather than replacing them, to include students who do not have access to the app. In the case of the Prep4DIT app, the authors incorporated a blog, Twitter feed, and a YouTube Channel into the app. However these can also be accessed independently by students using traditional platforms such as laptops or desktops. While this app project focused on dominant platforms of Google and Apple, future development should include development and deployment to the smaller but growing Windows Phone App Market.

Overall it can be concluded that this approach of hybrid app development offers real advantages over native development in complexity and ease of use for the non-technical individual. Hybrid app development allows for competitive pricing and rapid deployment, as well as providing an acceptable level of end user experience. With the development platform providing much of the infrastructure and software, educational institutions can benefit by providing innovative solutions for transition students with minimum levels in investment and technical skill.

\section{REFERENCES}

Baghdassarian, S. B., Ekholm, J., \& Shen, S. (2013). Predicts 2014: Apps, Personal Cloud and Data Analytics Will Drive New Consumer Interactions. Gartner, Inc.

Basole, R. C. (2009). Visualization of interfirm relations in a converging mobile ecosystem. Journal of Information Technology, 24(2), 144-159. doi:10.1057/jit.2008.34

Basole, R. C., \& Karla, J. (2012). Value transformation in the mobile service ecosystem: A study of app store emergence and growth. Service Science, 4(1).

Butler, M. (2011). Android: Changing the mobile landscape. Pervasive Computing, IEEE, 10(1), 4-7. doi:10.1109/MPRV.2011.1

Cappex. (2012). The Increasing Impact of Mobile Trends on College Admissions in 2012. Retrieved May 13, 2015, from https://www.cappex.com/media/digitalMobile2012.pdf

Charland, A., \& Leroux, B. (2011). Mobile application development: Web vs. native. Communications of the ACM, 54(5), 49. doi:10.1145/1941487.1941504

Christ, A. M. (2011). Bridging the mobile app gap. Connectivity and the User Experience, 11(1), 27-32.

Cuadrado, F., \& Dueñas, J. C. (2012). Mobile application stores: Success factors, existing approaches, and future developments. Communications Magazine, IEEE, 50(11), 160-167. doi:10.1109/ MCOM.2012.6353696

Curran, M., McKelvey, N., Curran, K., \& Nadarajah, S. (2015). Mobile App Stores. Retrieved June 9, 2015, from http://scisweb.ulster.ac.uk/ kevin/papers/IGI2014-mobileappstores.pdf 
Dahlstrom, E., Walker, J., \& Dziuban, C. (2013). ECAR Study of Undergraduate Students and Information Technology, 2013. EDUCAUSE Center for Analysis and Research Louisville, CO.

Department of Education and Science. (2004). A Brief Description Of the Irish Education System. Dublin: Department of Education and Skills.

Department of Education and Skills. (2010). Investing in Global Relationships - Irelands International Education Strategy 2010 - 15. Report of the High-Level Group on International Education to the Tánaiste and Minister for Education and Skills. Dublin: Department of Education and Skills.

Dublin Institute of Technology. (2010). DIT Strategy on Widening Participation. Retrieved June 2, 2015, from https://www.dit.ie/media/images/study/Strategy\%20on\%20Widening\%20Participation\%20 April\%202010.pdf

Edmondson, J., Anderson, W., Gray, J., Loyall, J. P., Schmid, K., \& White, J. (2014). Next-Generation Mobile Computing. Software, IEEE, 31(2), 44-47. doi:10.1109/MS.2014.39

Finn, M., \& O'Connell, P. J. (2012). Immigration of international students to the EU: Ireland. Dublin: ERSI.

Fling, B. (2009). Mobile design and development: Practical concepts and techniques for creating mobile sites and Web apps. O'Reilly Media, Inc.

Fotheringham, J., \& Alder, E. (2012). Getting the Message: supporting students' transition from Higher National to degree level study and the role of mobile technologies. Electronic Journal of e-Learning, $10(3), 262-272$.

Gartner. (2015). Gartner Says Smartphone Sales Surpassed One Billion Units in 2014 [Press release]. Retrieved May 2, 2015, from http://www.gartner.com/newsroom/id/2996817

Georgiev, M., Jana, S., \& Shmatikov, V. (2014). Breaking and fixing origin-based access control in hybrid web/mobile application frameworks. Paper presented at the NDSS symposium. doi:doi:10.14722/ ndss.2014.23323 doi:10.14722/ndss.2014.23323

Gupta, P., Gop, K., \& Kyei-Blankson, L. (2014). College students' usage of and expectations from university owned mobile applications. Paper presented at the World Conference on E-Learning in Corporate, Government, Healthcare, and Higher Education.

Hazelkorn, E. (2011). Rankings and the Reshaping of Higher Education: the Battle for World Wide Excellence. Dublin: Palgrave MacMillan. doi:10.1057/9780230306394

Heitkötter, H., Hanschke, S., \& Majchrzak, T. (2013). Evaluating Cross-Platform Development Approaches for Mobile Applications. In J. Cordeiro \& K. Krempels(Ed.), Web Information Systems and Technologies.8th International Conference (pp. 120-138). Berlin: Springer. doi:doi:10.1007/978-3-642-36608-6_8 doi:10.1007/978-3-642-36608-6_8

Henze, N., Pielot, M., Poppinga, B., Schinke, T., \& Boll, S. (2011). My app is an experiment: Experience from user studies in mobile app stores. International Journal of Mobile Human Computer Interaction, 3(4), 71-91. doi:10.4018/jmhci.2011100105 
Hingorani, K. K., Woodard, D., \& Askari-Danesh, N. (2012). Exploring How smartphones supports students' lives. Issues in Information Systems, 13(2).

Hunt, C. (2011). National strategy for higher education to 2030: Report of the Strategy Group. Dublin, Ireland: Department of Education and Skills.

IHEQN. (2006). Provision of Education to International Students: Code of Practice and Guidelines for Irish Higher Education Institutions. Dublin: Irish Higher Education Quality Network.

Kobus, M. B., Rietveld, P., \& Van Ommeren, J. N. (2013). Ownership versus on-campus use of mobile IT devices by university students. Computers \& Education, 68.

Kukulska-Hulme, A., Pettit, J., Bradley, L., Carvalho, A. A., Herrington, A., Kennedy, D., \& Walker, A. (2011). Mature students using mobile devices in life and learning. International Journal of Mobile and Blended Learning, 3(1), 18-52. doi:10.4018/jmbl.2011010102

Lan, Y.-F., \& Sie, Y.-S. (2010). Using RSS to support mobile learning based on media richness theory. Computers \& Education, 55(2), 723-732. doi:10.1016/j.compedu.2010.03.005

MacLean, S., Tausky, D., Labahn, G., Lank, E., \& Marzouk, M. (2011). Is the iPad useful for sketch input?: a comparison with the tablet PC. Paper presented at the Eighth Eurographics Symposium on Sketch-Based Interfaces and Modeling. doi:doi:10.1145/2021164.2021166 doi:10.1145/2021164.2021166

Manjunatha, A., Ranabahu, A., Sheth, A., \& Thirunarayan, K. (2010). Power of clouds in your pocket: An efficient approach for cloud mobile hybrid application development. Paper presented at the Cloud Computing Technology and Science (CloudCom), IEEE Second International Conference. doi:doi:10.1109/ CloudCom.2010.78 doi:10.1109/CloudCom.2010.78

Mao, X., \& Xin, J. (2014). Developing Cross-platform Mobile and Web Apps. CIGR Proceedings, I(1).

Oblinger, D., \& Oblinger, J. (2005). Is it age or IT: First steps toward understanding the net generation. Educating the Net Generation, 2(1-2).

Oblinger, D., Oblinger, J. L., \& Lippincott, J. K. (2005). Educating the net generation. Boulder, CO: EDUCAUSE.

Ozdamli, F. (2012). Pedagogical framework of m-learning. Procedia: Social and Behavioral Sciences, 31, 927-931. doi:10.1016/j.sbspro.2011.12.171

Pastore, S. (2014). Developing mobile educational apps: Development strategies, tools and business models. Advances in Computer Science: an International Journal, 3(1), 27-36.

Perkins, R., Shiel, G., Merriman, B., Cosgrove, J., \& Morgan, G. (2013). Learning for Life: The Achievements of 15 year olds on Mathematics, Reading Literacy and Science in PISA 2103. Dublin: Educational Research Centre.

Poyrazli, S., \& Grahame, K. M. (2007). Barriers to adjustment: Needs of international students within a semi-urban campus community. Journal of Instructional Psychology, 34(1), 28.

Prasad, M. R., Gyani, J., \& Murti, P. (2012). Mobile cloud computing: Implications and challenges. Journal of Information Engineering and Applications, 2(7), 7-15. 
Rajapakse, D. C. (2008). Techniques for De-fragmenting Mobile Applications: A Taxonomy. Paper presented at the SEKE, San Francisco, CA.

Russo, T. J., Fallon, M., Zhang, J., \& Acevedo, V. (2014). Today's University Students and Their Need to Connect. Retrieved April 12, 2015, from http://files.eric.ed.gov/fulltext/EJ1057527.pdf

Salz, P. A., \& Moranz, J. (2013). The Everything Guide to Mobile Apps: A Practical Guide to Affordable Mobile App Development for Your Business. Adams Media.

Sawir, E. (2005). Language Difficulties of International Students in Australia: The Effects of Prior Learning Experience. International Education Journal, 6(5), 567-580.

Schrock, K. (n.d.). Critical evaluation of a content-based mobile app. Retrieved November 16, 2014, from http://www.ipads4teaching.net/uploads/3/9/2/2/392267/evalipad_content.pdf

Schuetze, H. G., \& Slowey, M. (2002). Participation and exclusion: A comparative analysis of nontraditional students and lifelong learners in higher education. Higher Education, 44(3-4), 309-327. doi:10.1023/A:1019898114335

Schultz, L. (2007). Effects of graphical elements on perceived usefulness of a library. Retrieved February 16, 2013, from http://www.tarleton.edu/ schultz/finalprojectinternetsvcs.htm

Smith, A. (2013). Smartphone ownership-2013 update. Washington, DC: Pew Research Center.

Smith, M. E. (2014). Connecting students and families for support during the college transition. Paper presented at the companion publication of the 17th ACM conference on Computer supported cooperative work \& social computing. doi:doi:10.1145/2556420.2556832 doi:10.1145/2556420.2556832

Smith, R., \& Khawaja, N. (2011). A review of the acculturation experiences of international students. International Journal of Intercultural Relations, 35(6), 699-713. doi:10.1016/j.ijintrel.2011.08.004

Tapscott, D. (2008). Grown Up Digital: How the Net Generation is Changing Your World HC. London: McGraw-Hill.

Vincent, T. (2012). Education app evaluation rubric. Retrieved May 20, 2015, from: http://learninginhand.com/blog/evaluation-rubric-for-educational-apps.html

West, J., \& Mace, M. (2010). Browsing as the killer app: Explaining the rapid success of Apple's iPhone. Telecommunications Policy, 34(5).

Woodcock, B., Middleton, A. \& Nortcliffe, A. (2012). Considering the Smartphone Learner: developing innovation to investigate the opportunities for students and their interest. Student Engagement and Experience Journal, 1(1).

Xanthopoulos, S., \& Xinogalos, S. (2013). A comparative analysis of cross-platform development approaches for mobile applications. Paper presented at the 6th Balkan Conference in Informatics. doi:doi:10.1145/2490257.2490292 doi:10.1145/2490257.2490292

Zickuhr, K. (2013). Tablet Ownership 2013 - Pew Internet \& American Life Project. Retrieved January 20, 2015, from: http://www.pewinternet.org/2013/06/10/tablet-ownership-2013/ 


\section{KEY TERMS AND DEFINITIONS}

Access Students: Access students are primarily made up of mature students (23 years of age or over) and young adult students (below 23 years of age) from socioeconomically disadvantaged and educationally disadvantaged backgrounds who undertake Access Foundation Courses. These courses are tailored as pathways to higher education and prepare students with the necessary skills and knowledge required for their chosen undergraduate career.

Acculturation: Acculturation is the process of change that takes place as a result of a member of one culture joining another. For international students this would encompass societal, organisational, individual and language changes.

Bespoke Applications: Bespoke applications are applications that are specially developed for a specific organisation or group of users which can be contrasted with applications that are developed for the mass market.

Foundation Students: Foundation students comprise of Access and International Students participating on pre-degree foundation courses. These courses are tailored as pathways to higher education to prepare access and international students with the necessary skills and knowledge required for their particular undergraduate destination.

Hybrid Apps: Hybrid mobile applications are developed in a similar manner to websites by utilizing a combination of web technologies like HTML, CSS, and JavaScript. Instead of using a mobile browser a hybrid application is hosted inside a downloaded "native container" application which enables them to access the hardware capabilities of the mobile device and content from the internet.

International Students: International Students are defined as "third country nationals", people who are not EU citizens and who are accepted by a higher education institute for the purposes of studying in Ireland or another EU member state.

Mobile Application Development Platforms: Hybrid Mobile Development Platforms provide a way for developers to take advantage of web technologies and native platform features to release mobile apps on multiple platforms. They also abstract developers from the platform details.

Mobile Applications: Mobile applications are software that is developed for handheld devices, such as tablet computers or mobile phones, and usually downloaded and installed on the device from an App Store.

Transition Students: Transition typically refers to the transitional point in the education system, for example, when a student enters third level education from second level or work. Students in transition to third level education face complex and dynamic issues of diversity, in terms of their demographics, backgrounds and their preparedness for study in third level organisations. Many students that transition to third level can have preconceptions about what they might encounter, which may impact on their ability to perform academically or may ultimately influence their decision to drop out. 